Research paper

\title{
Hypolipidemic activity of P-methoxycinnamic diester (PCO-C) isolated from Copernicia prunífera against Triton WR-1339 and hyperlipidemic diet in mice
}

\author{
A.C.V.A. Filho ${ }^{a}$, P.A.S. Rodrigues ${ }^{a}, *$, S.R. Benjamin ${ }^{a}$, R.T.T. Paim ${ }^{a}$, M.O. Holanda ${ }^{a}$, J.Y.G. Silva ${ }^{a}$, \\ T.S. Milo ${ }^{a}$, I.G.P. Vieira ${ }^{a}$, M.G.R. Queiroz ${ }^{b}$, M.I.F. Guedes ${ }^{a}$ \\ ${ }^{a}$ Biotechnology and Molecular Biology Laboratory, State University of Ceará, Fortaleza, Ceará, Brazil \\ b Department of Odontology, Federal University of Ceará, Fortaleza, Ceará, Brazil
}

\section{A R T I C L E I N F O}

\section{Keywords:}

Carnauba wax

Cinnamic acid esters

Dyslipidemia

Triton WR-1339

Hyperlipidemic diet

\begin{abstract}
A B S T R A C T
Carnauba wax is extracted from the leaves of the Copernicia prunifera and contains approximately $80 \%$ of esters in its composition. The purpose of the present study was evaluate the hypolipidemic effect of p-methoxycinnamic diesters (PCO-C) extracted from Copernicia prunifera in a model of acute and chronic dyslipidemia in mice. The levels of total cholesterol and triglycerides were significantly reduced plasma levels in PCO-C at the dose of $100 \mathrm{mg} / \mathrm{kg}$ in a model of acute and chronic dyslipidemia. Histological studies showed that PCO-C has no hepatotoxic effect and reduces hepatic steatosis in animals that consumed hyperlipidemic ration. Thus, it was concluded that PCO-C isolated from Copernicia Prunifera was effective in reducing total cholesterol and triglyceride levels in both dyslipidemia induction models. The finding indicates that PCO-C might be beneficial in treatment of hyperlipidemia and atherosclerosis.
\end{abstract}

\section{Introduction}

Hyperlipidemia, is a chronic metabolic disease and has become one of the most common public health problems of global significance. It is characterized by the accumulation of excess blood lipid profiles, by elevated total cholesterol (TC), low-density lipoprotein cholesterol (LDL), and triglyceride (TG) levels (Soedamah-Muthu et al., 2003), resulting in risk complications such as cardiovascular diseases (CVD), stroke and myocardial infractions (Schmitz and Orsó, 2015). Furthermore, it is important to emphasize that cardiovascular diseases are still leading cause of death in Brazil (30\% of deaths), worldwide (17.5 million people), and also due to with tackling an unhealthy lifestyle, e.g. poor-quality diet, physical inactivity and smoking (Mozaffarian et al., 2016; Simão et al., 2013). The incidence of hyperlipidemia is gradually increasing, and may worsen with an aging population. Therefore, the prevention and management of hyperlipidemia is important (Dixon et al., 2015).

Currently for the treatment of dyslipidemias the hypolipidemic agents including statins, fibrates, and niacin represent the most common method of controlling lipid profiles (Sashidhara et al., 2010). Particularly, use of statins can reduce cholesterol synthesis or enhancing the clearance of triglyceride. However, use of statins are associated with several adverse effects, low efficacy in treatment and high cost of procurement (Ngono Ngane et al., 2011). Recently, the utilization of various medicinal plants of popular use have received considerable attention in treatment of the hyperlipidemia and prevent atherosclerosis in view of their valuable impacts (negligible side effects) (Xie et al., 2012).

Therefore, there is a strong interest around the world in natural hypolipidemic substances derived from medicinal plants. For this reason many natural products have received attention in this regard because they present significant hypolipidemic potential (Khanna et al., 2002).

Carnauba (Copernicia prunifera (Miller) H.E. Moore), Arecaceae family, is an economically important tree of the palm family in the northeastern region of Brazil. Carnauba wax is extracted from the leaves which contains complex mixture of esters, fatty acids, $\omega$-hydroxycarboxylic acids, triterpenoids, hydrocarbons (paraffins) and triterpene diols. Particularly, esters are the main component, corresponding to more than $80 \%$ of its composition. These esters are mainly composed of aliphatic esters and cinnamic acid diesters and has many applications in the cosmetics, pharmaceutical, food, and manufacturing

\footnotetext{
Abbreviations: ANOVA, analysis of variance; PCO-C, P-methoxycinnamic diester; TC, total cholesterol; LDL, low-density lipoprotein cholesterol; TG, triglyceride; CVD, cardiovascular

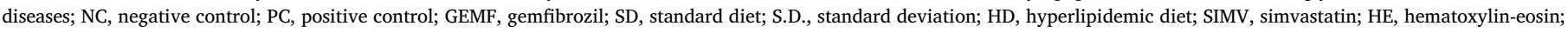
MCT, medium chain triglycerides; STZ, streptozotocin

* Corresponding author at: Biotechnology and Molecular Biology Laboratory, State University of Ceará, Fortaleza, Ceará 60740903, Brazil.

E-mail address: paulasalmito@yahoo.com.br (P.A.S. Rodrigues).
} 
industries (Fahlbusch, 2003).

However, despite their potential benefits of carnauba wax in the control of serum lipid levels, few studies have been currently reported. According to Guedes et al. (2011), who extracted p-methoxycinnamic diester (PCO-C), the main constituent of carnauba wax, observed a potential hypolipidemic and hypoglycemic effect in induction of dyslipidemia in mice. Additionally, Rodrigues et al. (2014), characterized the PCO-C and evaluated the biological activity of diabetes mellitus in mice induced by alloxan. Treatment with PCO-C (100 mg and $150 \mathrm{mg} /$ $\mathrm{kg}$ body weight) revealed hypoglycemic activity with significant therapeutic potential in chronic diseases.

Besides that to having effective biological activity for the treatment of chronic diseases, in study carried out by Freitas et al. (2016) demonstrated the high thermal stability of PCO-C, as well as its high antioxidant potential, showing promise for the pharmaceutical and food industries.

Therefore, the objective of in this study was to evaluate the therapeutic potential of the PCO-C regarding the reduction of plasma lipid levels in in vivo experimental models of acute and chronic hyperlipidemia, bringing new perspectives to the natural substance under study, contributing to the knowledge and possible elaboration of an effective phytoterapic product of this compound, providing to the biotechnological development of the Brazilian northeast region.

\section{Materials and methods}

\subsection{Materials and reagents}

The carnauba wax was obtained from Pontes Indústria de Ceras Ltda., Fortaleza, CE, Brazil. Cholic acid (Inlab ${ }^{\circ}$ ) was obtained from Medical laboratory (Sao Luis, MA, Brazil); Cholesterol, Ethylene Dichloride P.A., Ethanol P.A., Formic aldehyde., Heptane P.A., Isopropanol P.A., and Silica gel (Vetec ${ }^{\circ}$ ) for the column were purchased from the Vetec Quimica Fina Ltda - Brazil. Sodium heparin (Cristalia) was purchased from Cristália (Itapira, SP, Brazil), Kits for biochemical and hematological analysis were purchased from Labtest ${ }^{\circ}$ (Lagoa Santa, MG, Brazil). Polysorbate 80 (Tween 80)., Triton WR-1339 (tyloxapol), were purchased from the Sigma-Aldrich Co. (St. Louis, MO, USA); Simvastatin and gemfibrozil were purchased from the Merck \& Co., Inc. (Whitehouse Station, NJ - USA). All other reagents and solvents used in this research were of analytical grade.

\subsection{Isolation and purification of PCO-C from the carnauba wax (C. prunifera)}

The chemical characterization of the substance referred to herein as PCO-C has previously been described by Freitas et al. (2016).

Extraction of the carnauba wax powder $40 \mathrm{~g}$ (eye powder - powder extracted from carnauba unopened leaves), was performed by using an $500 \mathrm{~mL}$ mixture of heptane and ethylene dichloride (9:1) was used. After filtration, the mixture was added to a Florisil column $(46 \times 3.8 \mathrm{~cm}$, first column), which was eluted with $2.5 \mathrm{~L}$ of a mixture of heptane and ethylene dichloride (9:1). All material eluted from the first column was collected and added to a second column of Silica gel of the same size as the previous one $(46 \mathrm{~cm} \times 3.8 \mathrm{~cm}$; second column). After percolation of the eluate an additional $500 \mathrm{~mL}$ of a mixture of heptane and ethylene dichloride (9:1) was added to the silica gel column. The eluted solvent was concentrated to obtain the aliphatic esters of the carnauba wax. For the second column (Silica Gel) 2.0L of a mixture of heptane and isopropanol (9:1) were then added. The solvent eluted from the column was concentrated, yielding $1.68 \mathrm{~g}(4.2 \%)$ of a yellowish solid product called PCO-C. The filtration residue was allowed to stand at room temperature until complete evaporation of the solvent. The PCO-C consists of a mixture of aromatic esters and this compound was identified as 4-methoxycinnamic acid diester and was isolated and characterized following the methodology described by
Vandenburg and Wilder (1967).

\subsection{Experimental animals}

The animals were kept in polypropylene boxes of the Biotechnology and Molecular Biology laboratory in State University of Ceará (Fortaleza, Ceará - Brazil), at $22 \pm 2{ }^{\circ} \mathrm{C}$ in light/dark cycles $(12 \mathrm{~h} /$ $12 \mathrm{~h}$ ), receiving standard diet and water ad libitum. The antihyperlipidemic activity of PCO-C was performed on male Swiss mice, weighing between 25-30 g, obtained from the Central Vivarium of the Federal University of Ceará. All experimental procedures with the animals were approved by the Research Ethics Committee of the Federal University of Ceará under number 90/10.

\subsection{Induction of acute dyslipidemia by Triton WR-1339}

Acute dyslipidemia was induced by administration of a single intraperitoneal injection of Triton WR-1339 dissolved in phosphate buffered saline (pH 7.4) at a dose of $400 \mathrm{mg} / \mathrm{kg}$. The animals were divided into six groups $(n=7)$ and received of the respective names and treatments: Negative Control (NC), healthy animals treated with saline; Positive Control (PC), animals receiving triton injection and was treated with saline; Group animals treated with Gemfibrozil (GEMF-100 mg/ $\mathrm{kg}$ ). Animals receiving PCO-C were divided into three groups and treated with the following doses: 10,50 and $100 \mathrm{mg} / \mathrm{kg}$, respectively. The groups were treated in three different times: one hour before, 22 and $46 \mathrm{~h}$ after Triton WR-1339 administration.

\subsection{Induction of dyslipidemia by hyperlipidemic diet}

Male Swiss mice weighing 25-30 g, were made hyperlipidemic by being fed on high-fat diet (HFD) obtained from Nuvilab ${ }^{\circ}$ (Nuvilab, Paraná, Brazil, for 15 days). The HFD contained 10\% coconut oil, $1 \%$ cholesterol and $0.1 \%$ cholic acid as major constituents (Wilson et al., 2007). The mice were acclimatized for 1 week before the experiment. After that period, heparinized blood samples were collected for confirmation of dyslipidemia. The mice continued to receive this ration and were divided into six groups $(n=7)$ receiving the following treatments during two months: the group Standard Diet (SD) was fed normal food and saline; the group Hyperlipidemic Diet (HD) was fed an enriched fat diet and saline; Animals receiving PCO-C10, PCO-C50 and PCO-C100 were fed enriched fat diet and receiving the following doses: 10, 50 and $100 \mathrm{mg} / \mathrm{kg}$, respectively; and the group was fed an enriched fat diet and received simvastatin (SIMV) at a dose of $20 \mathrm{mg} / \mathrm{kg}$.

At the end of each month of treatment, the animals were starved for $8 \mathrm{~h}$ to analyze serum levels of total cholesterol (TC) and triglycerides (TG). In this protocol of induction of chronic dyslipidemia through the hyperlipidemic experimental diet, PCO-C, Simvastatin and Gemfibrozil were dissolved in a solution with Tween 80 (polysorbate) at $3 \%(\mathrm{v} / \mathrm{v})$.

\subsection{Sample collection and processing}

The blood samples were collected from the retro-orbital plexus of the animals and the blood plasma was centrifuged at $3500 \mathrm{rpm}$ for $15 \mathrm{~min}$ at room temperature. Plasma TC and TG values were measured using the technical recommendations contained in the manufacturers' kits Bioclin (Fortaleza, Ceará, Brazil).

\subsection{Histological analysis}

At the end of the treatment period, animals from each group selected randomly were sacrificed and liver were dissected out. A portion of the liver tissue was fixed in $10 \%$ buffered neutral formalin for histological studies. After fixation, tissues were embedded in paraffin; solid sections were cut at 4-5 $\mu \mathrm{m}$ thickness and stained with eosin and Hematoxylin-Eosin (HE). The sections were examined under light 
microscopy (NIKON YS2) and the photomicrographs of the tissues were made through a digital photographic camera (NIKON COOLPIX L14 7.1 megapixels).

\subsection{Statistical analysis}

The data are expressed as mean \pm standard deviation (S.D). The significance of differences between the animals from the groups was assessed using analysis of variance (ANOVA), followed by the NewmanKeuls test. A value of $p<0.05$ was considered significant.

\section{Results}

\subsection{Effect of PCO-C on serum lipid profile in Triton WR-1339 induced hyperlipidemic mice}

After injection of triton $(400 \mathrm{mg} / \mathrm{kg})$, there was a significant increase in the lipid levels of the animals. Total cholesterol levels were statistically higher in the CP group after $24 \mathrm{~h}(420 \% \mathrm{p}<0.05)$ and $48 \mathrm{~h}(257.14 \% \mathrm{p}<0.05)$ when compared to the $\mathrm{CN}$ group. There was also a significant increase in triglyceride levels in $24 \mathrm{~h}(15.00 \%$ $\mathrm{p}<0.05)$ and $48 \mathrm{~h}(83.05 \% \mathrm{p}<0.05)$ in the CP group when compared to NC (Table 1).

A significant hypocholesterolemic effect $(\mathrm{p}<0.05)$ of PCO-C was observed at the concentrations of 50 and $100 \mathrm{mg} / \mathrm{kg}$ with results of 353.0 and $372.3 \mathrm{mg} / \mathrm{dL}$ (Table 1), respectively, when compared to PC group $(587.7 \mathrm{mg} / \mathrm{dL})$. Regarding plasma TG levels, the results showed a reduction of this parameter $(\mathrm{p}<0.05)$ in the groups that received PCO-C at a dose of $100 \mathrm{mg} / \mathrm{kg}(3860.0 \mathrm{mg} / \mathrm{dL})$ and GEMF $(2573.0 \mathrm{mg} /$ $\mathrm{dL}$ ), compared to the PC group ( $4642.00 \mathrm{mg} / \mathrm{dL}$ ). The same behavior was observed after $48 \mathrm{~h}$ of induction with triton (Table 1), that is, the PCO-C50 and PCO-C100 groups showed a reduction significant ( $p<0.05$ ) of plasma cholesterol levels with values of 207.7 and $175.5 \mathrm{mg} / \mathrm{dL}$, respectively, compared to the PC group $(322.2 \mathrm{mg} / \mathrm{dL})$. However, only the PCO-C100 (458.5 mg/dL) and GEMF (682.7 mg/dL) groups dramatically decreased TG levels compared at the PC group (1426.0 mg/dL).

\subsection{Diet-induced hyperlipidemia}

At 60 days of treatment the PCO-C also showed an effective effect in reducing TC levels at all doses administered, presenting the following values: $195.2 \mathrm{mg} / \mathrm{dL}$ (PCO-C10); $187.0 \mathrm{mg} / \mathrm{dL} \quad$ (PCO-C50) and $147.2 \mathrm{mg} / \mathrm{dL}$ (PCO-C100). These results were very similar to those the group that received the standard drug (SIMV $197.2 \mathrm{mg} / \mathrm{dL}$ ), which demonstrates that the PCO-C had the same effectiveness in reducing TC levels when compared to the HD group $(271.8 \mathrm{mg} / \mathrm{dL})$. In addition, at the end of the second month of treatment, the PCO-C in the dose of $100 \mathrm{mg} / \mathrm{kg}$ had a better hypolipidemic effect than the standard drug (Simvastatin), with a higher percentage of reduction in plasma TC levels (Table 2).
The Newman-Keuls test showed that treatment with PCO-C at all doses and Simvastatin significantly reduced plasma levels of TC $(\mathrm{P}<0.05)$ at the 30th day of treatment. The observed values were 258.7, 218.8, 193.3 and $186.0 \mathrm{mg} / \mathrm{dL}$ for the PCO-C10, PCO-C50, PCOC100 and SIMV, respectively, compared to the HD group $(234.2 \mathrm{mg} / \mathrm{dL})$ (Table 2). Besides that, animals that consumed the hyperlipidemic ration and were treated with PCO-C100 and SIMV had a significant reduction in levels TC, $17.5 \%$ and $20.6 \%$, respectively, in relation to the PC group. Regarding triglycerides, the diet was not able to change this parameter during the first 30 days of the experiment. In addition, after 60 days, the hyperlipidemic diet caused a significant reduction in the triglyceride levels and the treatments used did not alter this parameter (Table 2).

\subsection{Histopathological observation}

In the analysis of the liver of the animals submitted to the protocol with a hyperlipidemic diet and to the treatment with PCO-C and simvastatin, it was verified that this diet promoted a high deposition of hepatic fat (Fig. 1B), compatible with steatosis, compared to the SD group, which received only standard diet (Fig. 1A). In addition, it may be considered that the PCO-C promoted a protective hepatic effect, as was observed in histological analysis that showing reduction in hepatic fat deposition (Fig. 1D).

The treatments with PCO-C (Fig. 1C) and Simvastatin (Fig. 1D) were able to decrease the deposition of fat in the liver, when compared to the HD group, as can be observed in Fig. 1B (group treated with a hyperlipidemic diet).

\section{Discussion}

Hyperlipidemia is characterized as elevation in triglycerides and cholesterol in the blood this way the most conceivable procedure in evaluating hyperlipidemia is utilizing drugs that contains mixture of compounds which can defer fat digestion and ingestion through gastrointestinal tract by repressing pancreatic lipase and pancreatic cholesterol esterase activities (García-Fuentes et al., 2000; Lusis, 2000).

The non-ionic detergent, Triton WR-1339, has been generally used to hinder the uptake of triacyl glycerol-rich lipoproteins from plasma by peripheral tissues in order to produce acute hyperlipidemia in animal models which are regularly utilized for a numerous of objectives, in particular for screen characteristic or compound hypolipidemic drugs. With this point, numerous therapeutic plants have been surveyed for their hypolipidemic action in a Triton WR-1339-induced hyperlipidemic model (Ibrahim et al., 2016).

In the present work, we have investigated the same strategy using a murine model induced by Triton WR-1339 and hyperlipidemic diet assessed for their hypolipidemic activity of p-methoxycinnamic diesters (PCO-C) extracted from Copernicia prunífera. In recent years several studies have been reporting the therapeutic potential of natural products in the treatment of chronic non-communicable diseases (Hasani-

Table 1

Effect of the PCO-C and gemfibrozil on plasma concentrations of total cholesterol and triglycerides in Triton WR1339-induced dyslipidemia.

\begin{tabular}{|c|c|c|c|c|c|c|c|}
\hline Time & & NC & PC & PCO-C10 & PCO-C50 & PCO-C100 & GEMF \\
\hline \multirow[t]{2}{*}{$24 \mathrm{~h}$} & $\mathrm{TC}$ & $139.3 \pm 9.7$ & $587.7 \pm 43.4^{*}$ & $646.2 \pm 56.9^{*}$ & $353.0 \pm 61.4^{*, \ldots * x}$ & $372.3 \pm 86.3^{*,+, k x}$ & $390.363 .3^{\text {k, ,k* }}$ \\
\hline & TG & $92.8 \pm 7.8$ & $4642.0 \pm 274.8$ & $4684.0 \pm 448.5^{*}$ & $4551.0 \pm 416.6^{*}$ & $3860.0 \pm 805.2^{*, * k}$ & $2573.0 \pm 340.0^{*, k * x}$ \\
\hline \multirow[t]{2}{*}{$48 \mathrm{~h}$} & $\mathrm{TC}$ & $125.3 \pm 11.0$ & $322.2 \pm 79.4^{*}$ & $310.7 \pm 56.5^{*}$ & $207.7 \pm 84.8^{* * *}$ & $175.5 \pm 35.5^{* k \hbar}$ & $232.5 \pm 55.4^{*, \ldots k}$ \\
\hline & TG & $171.7 \pm 43.9$ & $1426.0 \pm 276.7^{*}$ & $1428.0 \pm 419.9^{*}$ & $1153.0 \pm 416.8^{*}$ & $458.5 \pm 235.0^{\text {*** }}$ & $682.7 \pm 216.2^{*, k * k}$ \\
\hline
\end{tabular}

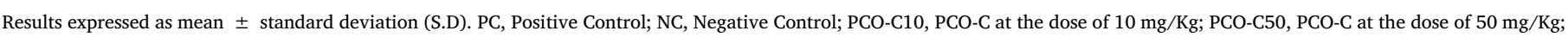

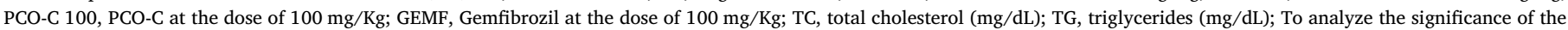
differences between the samples of authors used Analysis of Variance (ANOVA) followed by the Newman-Keuls comparison test.

$* \mathrm{p}<0.05$ vs CN.

** $\mathrm{p}<0.05$ vs PC. 
Table 2

Effect of the PCO-C and simvastatin on plasma concentrations of total cholesterol and triglycerides in hyperlipidemic diet induced dyslipidemia.

\begin{tabular}{|c|c|c|c|c|c|c|c|}
\hline Time & & SD & HD & PCO-C10 & PCO-C50 & PCO-C100 & SIMV \\
\hline \multirow[t]{2}{*}{ Month 1} & TC & $134.2 \pm 11.7$ & $234.2 \pm 8.8^{*}$ & $258.7 \pm 12.2^{*, * * k}$ & $218.8 \pm 11.4^{*, k * k}$ & $193.3 \pm 13.5^{*, * * k}$ & $186.0 \pm 17.4^{*, \ldots, k x}$ \\
\hline & TG & $162.9 \pm 24.0$ & $134.6 \pm 28.4$ & $138.9 \pm 51.2$ & $134.1 \pm 53.4$ & $105.3 \pm 28.2$ & $105.4 \pm 19.7$ \\
\hline \multirow[t]{2}{*}{ Month 2} & TC & $145.3 \pm 9.3$ & $271.8 \pm 22.2^{*}$ & $195.2 \pm 14.6^{*, * * k}$ & $187.0 \pm 9.2^{*, * *}$ & $147.2 \pm 9.6^{* * *}$ & $197.2 \pm 4.6^{*, 2, k+k}$ \\
\hline & TG & $149.9 \pm 45.8$ & $98.0 \pm 15.3^{*}$ & $99.5 \pm 23.1^{k}$ & $108.4 \pm 11.8^{*}$ & $90.1 \pm 35.5^{*}$ & $94.8 \pm 19.8^{*}$ \\
\hline
\end{tabular}

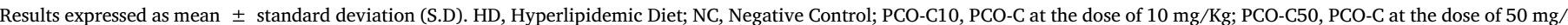

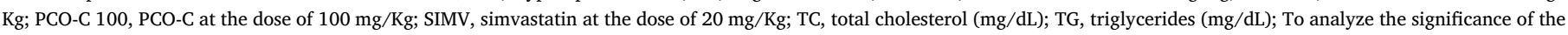
differences between the samples of authors used Analysis of Variance (ANOVA) followed by the Newman-Keuls comparison test.

$* \mathrm{p}<0.05$ vs SD.

$* * \mathrm{p}<0.05$ vs HD.
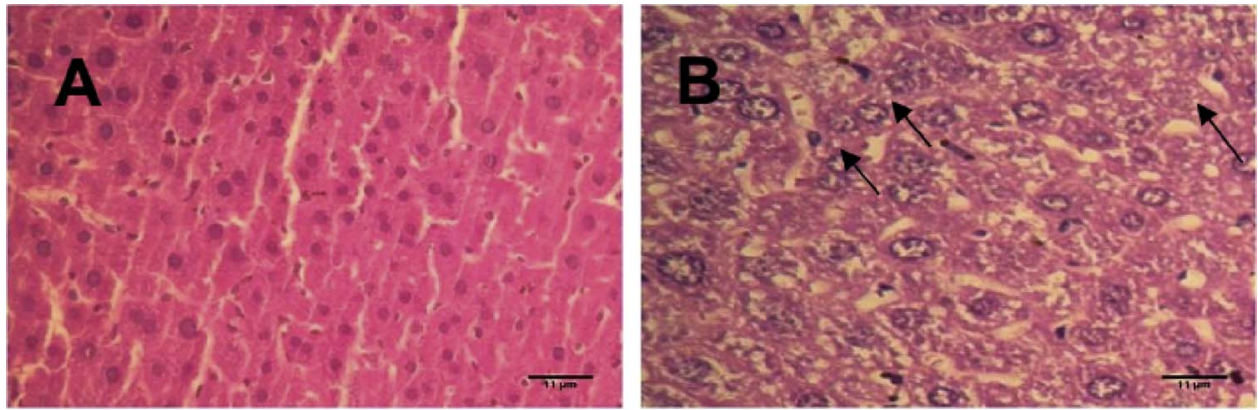

Fig. 1. Representative micrograph of the liver of the animals of the control and the animals treated with PCO-C and Simvastatin. SD, Standard Diet (A); HD, Hyperlipidemic Diet (B); PCO-C $100 \mathrm{mg} / \mathrm{kg}$ (C); SIMV, Simvastatin $20 \mathrm{mg} / \mathrm{kg}$ (D). The structures analyzed by optical microscopy demonstrate normality patterns for Fig. 1A, fatty deposit of a marked size, compatible with steatosis for Fig. 1B and decrease in that deposition pattern for Fig. $1 \mathrm{C}$ and $\mathrm{D}$ in the $400 \times$ magnification. The arrows indicate vacuolations compatible with deposition of lipid material visible in optical microscopy.
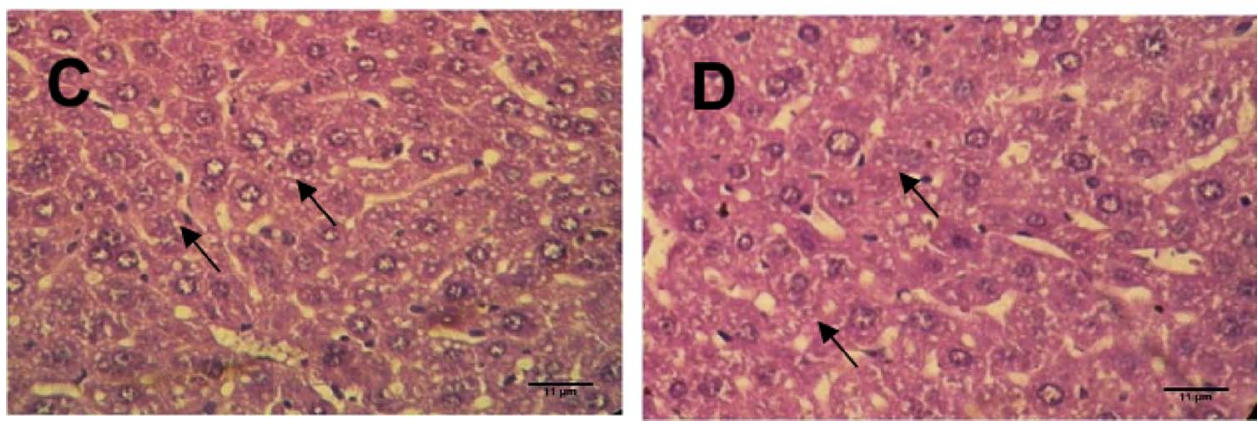

Ranjbar et al., 2010) among them highlight the gamma-oryzanol (which is extracted from rice bran oil) and policosanol (present in sugar cane wax) that have already been reported in the treatment of dyslipidemia and diabetes. These products have a chemical structure very similar to PCO-C (Berthold et al., 2006; Guedes et al., 2011).

In our study, we observed the increase in the levels of total cholesterol (3.0-times higher than the control group) and triglycerides (12.5-times higher than the control group) $24 \mathrm{~h}$ after a single Triton WR-1339 injection in mice. The results demonstrated here were in accordance with those reported by others (Modak et al., 2007; Mohammadi et al., 2015).

However, in the induction of chronic dyslipidemia by diet there was an increase only in the plasma levels of TC. In this induction protocol the hyperlipidemic diet was not able to alter TG plasma levels (Table 2). This fact can be explained by the presence of coconut oil in the hyperlipidemic diet, because this food has approximately $92 \%$ saturated fatty acids in its composition, among which the Medium Chain Triglycerides (MCT), which contribute to elevated TC levels, but reduce plasma triglycerides levels (Chandrashekar et al., 2010).

It is clear from our results that the PCO-C from this plant decrease plasma total cholesterol in a marked manner, both at 24 and $48 \mathrm{~h}$ after Triton treatment. The reduction of plasma total cholesterol was associated with a decrease of its LDL fraction which is a major, potentially modifiable risk factor of cardiovascular diseases and the target of many hypocholesterolemic therapies. This finding suggests that the cholesterol-lowering activity of these extracts appears to be due to the enhancement of LDL-C catabolism (McCoy et al., 2002).
A similar result was observed in our study through induction of Triton dyslipidemia where was verified that the animals treated with PCO-C showed a significant reduction in TG levels. The highest reduction in TG levels occurred in the 48-h period after induction by Triton, where there was a decrease of $67.8 \%$ (PCO-C $100 \mathrm{mg} / \mathrm{kg}$ ) at the levels of TG when compared to the PC group. This percentage reduction was greater than that presented by the standard drug gemfibrozil $(52.1 \%)$. These results were very similar to the study realized by Ghatak and Panchal (2012) regarding TG levels, which used gama orizanol at doses of 50 and $100 \mathrm{mg} / \mathrm{kg}$ in the treatment of triton-induced dyslipidemia in mice, and found a high reduction of TG levels, with reduction greater than $65 \%$ in relation to the PC group.

Regarding the cholesterol data, it can be observed that in the induction by Triton WR-1339 the PCO-C was effective in reducing the serum levels of this parameter, the dose of $50 \mathrm{mg} / \mathrm{kg}$ being that the presented with the greatest reduction (45.5\%) when compared to the PC group. In the induction of chronic dyslipidemia by diet at the end of the first month of treatment, animals that consumed the hyperlipidemic ration and were treated with PCO-C $(100 \mathrm{mg} / \mathrm{kg})$ and SIMV $(20 \mathrm{mg} / \mathrm{kg})$ had a significant reduction in TC levels $(17.5 \%$ and $20.6 \%$, respectively) in relation to the PC group. In addition, at the end of the second month of treatment, the PCO-C in the dose of $100 \mathrm{mg} / \mathrm{kg}$ had a better hypolipidemic effect than the standard drug (Simvastatin), with a higher percentage of reduction in plasma TC levels (Table 2).

These results are in accordance with those of (Chandrashekar et al., 2010; Ma et al., 2015) who reported that used gamma oryzanol and Cyclocarya paliurus (Batal.), substances already reported in the 
literature with lipid-lowering potential and which are chemically very similar to PCO-C, in a model of chronic dyslipidemia, the PCO-C showed greater potential of the reducing plasma levels of TC (reduction greater than $40 \%$ ) in chronic dyslipidemia model in mice. These findings suggest that the cholesterol-lowering activity of PCO-C probably mediated through the enhanced catabolism of LDL-C that may be mediated by hepatic receptors.

Taking into account the mechanism by which Triton elevates TG and TC levels the results of our study suggest that PCO-C is possibly capable of transferring apo C-II from HDL to VLDL, a fact that stimulates the lipolytic activity of LPL and, consequently, the hydrolysis of plasma TG (McCoy et al., 2002). This finding suggests that the hypolipidemic activity of the PCO-C appears to be due to increased LDL-C catabolism. However, further studies are needed to identify the exact mechanism of action of how the PCO-C was able to restore imbalance in TG metabolism after induction by Triton.

Recently, a number of clinical studies suggest that the increased risk of coronary heart disease is associated with a high serum concentration of TC, LDL-C and triglyceride. The abnormally high concentration of serum lipids is mainly due to the increase in the mobilization of free fatty acids from the peripheral depots (Xie et al., 2012). On the other hand, low serum concentration of HDL-C is also responsible for coronary heart disease (Xie et al., 2012). Free radicals and other reactive oxygen species are considered to be important causative factors in the development of diseases of aging such as neurodegenerative diseases, cancer and cardiovascular diseases. Phytochemicals have long been recognized to possess many properties including antioxidant, anti-allergic, anti-inflammatory, antiviral, anti-proliferative and anti-carcinogenic. This relationship has led to considerable interest in assessing the antioxidant capacity of foods, botanicals and other nutritional antioxidant supplements. As plants produce significant amount of antioxidants to prevent the oxidative stress caused by photons and oxygen, they represent a potential source of new compounds with antioxidant activity. Thus, continued research is being undertaken all over the world on different plant species and their therapeutic principles.

Recently, Marques et al. (Marques et al., 2014) studied several cinnamic acids and distinguished the structures that contribute to the biological activity of these compounds, including the presence of substituents on the electron-donating aromatic ring (hydroxyl and/or methoxyl) and the carboxylic radical with an adjacent unsaturated double bond, which provides additional attack sites for free radicals and acts as an anchor for the lipid bilayer. The presence of $p$-methoxycinnamic acid (PCO-C) in the form of an ester possibly increases its antioxidant potential, as Jakovetic et al. (Jakovetić et al., 2013) reported that esterification expanded the antioxidant activity of cinnamic acid and its derivatives.

Taking into consideration that the latter was studied at a low concentration and extrapolating for the same concentration of the former, it can be concluded that the second compound had 26 times greater antiradical activity. In p-methoxycinnamic acid, the methoxy group is an electron-donating group (Jakovetić et al., 2013).

The possible mechanism of this activity may result from the enhancement of lecithin cholesteryl acyl transferase (LCAT) and inhibition of hepatic triglyceride lipase (HTL) on HDL which may lead to a rapid catabolism of blood lipids through extrahepatic tissues. It is also reported that triglycerides play a key role in the regulation of lipoprotein interactions to maintain normal lipid metabolism. Indeed, the elevated plasma TGs levels were associated with an increased incidence of coronary artery disease. Moreover, these higher plasma TG levels have been attributed mainly to an increased population of small, dense LDL deposits which are very atherogenic and enhanced cholesteryl ester mass transfer from apolipoprotein B-containing lipoproteins (VLDL and LDL). TGs have also been proposed to be a major determinant of cholesterol esterification, its transfer and HDL remodeling in human plasma (Paim et al., 2017).

In the present study, no hepatotoxic effect was observed on the concentrations of PCO-C used (Fig. 1). This fact is very relevant because some preparations of medicinal herbs, conventional medicines and chemical substances can cause damage to the structure of several organs due to their toxicity (Rodrigues da Silva et al., 2015, 2015; Asare et al., 2012). In addition, it may be considered that the PCO-C promoted a protective hepatic effect, as was observed in histological analysis that showing reduction in hepatic fat deposition (Fig. 1D).

The histopathological findings of the present study corroborate with the results of the work done by Ma et al. (2015) and He et al. (2015) that used extracts of plants rich in polyphenols to treat dyslipidemic animals. In these studies, a reduction of hepatic steatosis was observed in the animals treated with the extracts of the plants when compared to the positive control group, same fact was also verified in the present study.

In a study that evaluated an extract of Cichorium intybus (chicory), composed mainly of chlorogenic acid, chicoric acid, caffeic acid and caftaric acid, which are derivatives of hydroxycinnamic acid, demonstrated that this compound reversed severe damage, such as steatosis, to liver of the tissues from rats receiving Streptozotocin (STZ), as well as reducing the triglyceride content of steatotic cells, improving the histopathological characteristics of hepatic tissues (Ziamajidi et al., 2013) through its possible high antioxidant capacity that combats the toxicity of free fatty acids, neutralizing various types of free radicals, without the need for the synthesis of triglyceride (Meyer and Frankel, 2001).

\section{Conclusions}

Results of this study concluded that PCO-C has a significant hypolipidemic potential, being higher in the dose of $100 \mathrm{mg} / \mathrm{kg}$. Thus, these results suggest that the PCO-C may be an effective agent in lipid reduction as well as a potential preventive agent for the development of cardiovascular diseases caused by changes in lipid metabolism. Although the mechanism of action for the activity of such compound cannot be accurately stated, the results of the experimental protocols performed here are suggestive that it the PCO-C can act in the increase of plasma LPL activity, as well as in the reduction of the tissue LPL activity.

\section{Conflict of interest statement}

We declare that we have no conflict of interest.

\section{Acknowledgements}

The authors thank the FUNCAP (Fundação de Amparo a Pesquisa do Estado do Ceará) and BNB (Banco do Nordeste do Brazil) for their financial support.

\section{References}

Asare, G.A., Bugyei, K., Sittie, A., Yahaya, E.S., Gyan, B., Adjei, S., Addo, P., Wiredu, E.K., Adjei, D.N., Nyarko, A.K., 2012. Genotoxicity, cytotoxicity and toxicological evaluation of whole plant extracts of the medicinal plant Phyllanthus niruri (Phyllanthaceae). Genet. Mol. Res. 11, 100-111. http://dx.doi.org/10.4238/2012. January.13.3.

Berthold, H.K., Unverdorben, S., Degenhardt, R., Bulitta, M., Gouni-Berthold, I., 2006. Effect of policosanol on lipid levels among patients with hypercholesterolemia or combined hyperlipidemia: a randomized controlled trial. JAMA 295, 2262-2269. http://dx.doi.org/10.1001/jama.295.19.2262.

Chandrashekar, P., Lokesh, B.R., Gopala Krishna, A.G., 2010. Hypolipidemic effect of blends of coconut oil with soybean oil or sunflower oil in experimental rats. Food Chem. 123, 728-733. http://dx.doi.org/10.1016/j.foodchem.2010.05.042.

Dixon, D.L., Donohoe, K.L., Ogbonna, K.C., Barden, S.M., 2015. Current drug treatment of hyperlipidemia in older adults. Drugs Aging. http://dx.doi.org/10.1007/s40266-0150240-6.

Fahlbusch, K.-G., 2003. Ullmann's encyclopedia of industrial chemistry. Ullmann's Encyclopedia of Industrial Chemistry. pp. 73-198. http://dx.doi.org/10.1002/ 14356007.

Freitas, C.A.S., Vieira, Í.G.P., Sousa, P.H.M., Muniz, C.R., Gonzaga, M.L.D.C., Guedes, M.I.F., 2016. Carnauba wax p-methoxycinnamic diesters: characterisation, 
antioxidant activity and simulated gastrointestinal digestion followed by in vitro bioaccessibility. Food Chem. 196, 1293-1300. http://dx.doi.org/10.1016/j. foodchem.2015.10.101.

Ghatak, S.B., Panchal, S.S., 2012. Anti-diabetic activity of oryzanol and its relationship with the anti-oxidant property. Int. J. Diabetes Dev. Ctries. 32, 185-192. http://dx. doi.org/10.1007/s13410-012-0086-y.

Guedes, Izabel Florindo, Mendes, F.N.P., de Queiroz, G.R., Vieira, Í.G.P., Guedes, I.F., de Almeida, L.M., Duarte, L.S.F., 2011. Production, Use and Pharmaceutical Composition Process Understanding Compounds Obtained from the CarnaÚba Wax.

Hasani-Ranjbar, S., Nayebi, N., Moradi, L., Mehri, A., Larijani, B., Abdollahi, M., 2010. The efficacy and safety of herbal medicines used in the treatment of hyperlipidemia; a systematic review. Curr. Pharm. Des. 16, 2935-2947.

He, L., Hao, L., Fu, X., Huang, M., Li, R., 2015. Severe hypertriglyceridemia and hypercholesterolemia accelerating renal injury: a novel model of type 1 diabetic hamsters induced by short-term high-fat/high-cholesterol diet and low-dose streptozotocin. BMC Nephrol. 16, 51. http://dx.doi.org/10.1186/s12882-015-0041-5.

Jakovetić, S.M., Jugović, B.Z., Gvozdenović, M.M., Bezbradica, D.I., Antov, M.G., Mijin, D.Ž., Knežević-Jugović, Z.D., 2013. Synthesis of aliphatic esters of cinnamic acid as potential lipophilic antioxidants catalyzed by lipase B from candida antarctica. Appl. Biochem. Biotechnol. 170, 1560-1573. http://dx.doi.org/10.1007/s12010-0130294-z.

Khanna, A.K., Rizvi, F., Chander, R., 2002. Lipid lowering activity of Phyllanthus niruri in hyperlipemic rats. J. Ethnopharmacol. 82, 19-22. http://dx.doi.org/10.1016/S03788741(02)00136-8.

Ma, Y., Jiang, C., Yao, N., Li, Y., Wang, Q., Fang, S., Shang, X., Zhao, M., Che, C., Ni, Y., Zhang, J., Yin, Z., 2015. Antihyperlipidemic effect of Cyclocarya paliurus (Batal.) Iljinskaja extract and inhibition of apolipoprotein B48 overproduction in hyperlipidemic mice. J. Ethnopharmacol. 166, 286-296. http://dx.doi.org/10.1016/j.jep. 2015.03.030.

Marques, M.P.M., Batista de Carvalho, L.A.E., Valero, R., Machado, N.F.L., Parker, S.F., 2014. An inelastic neutron scattering study of dietary phenolic acids. Phys. Chem. Chem. Phys. 16, 7491-7500. http://dx.doi.org/10.1039/c4cp00338a.

McCoy, M.G., Sun, G.-S., Marchadier, D., Maugeais, C., Glick, J.M., Rader, D.J., 2002. Characterization of the lipolytic activity of endothelial lipase. J. Lipid Res. 43, 921-929.

Meyer, A.S., Frankel, E.N., 2001. Antioxidant activity of hydroxycinnamic acids on human low-density lipoprotein oxidation. Methods Enzymol. 335, 256-265.

Modak, M., Dixit, P., Londhe, J., Ghaskadbi, S., Paul, a D.T., 2007. Indian herbs and herbal drugs used for the treatment of diabetes. J. Clin. Biochem. Nutr. 40, 163-173. http://dx.doi.org/10.3164/jcbn.40.163.

Mohammadi, A., Kazemipour, M., Ranjbar, H., Walker, R.B., Ansari, M., 2015. Amoxicillin removal from aqueous media using multi walled carbon nanotubes. Fullerenes Nanotubes Carbon Nanostruct. 23, 165-169. http://dx.doi.org/10.1080/ 1536383X.2013.866944.

Mozaffarian, D., Benjamin, E.J., Go, A.S., Arnett, D.K., Blaha, M.J., Cushman, M., Das, S.R., Ferranti, S., De Després, J.P., Fullerton, H.J., Howard, V.J., Huffman, M.D., Isasi, C.R., Jiménez, M.C., Judd, S.E., Kissela, B.M., Lichtman, J.H., Lisabeth, L.D., Liu, S., MacKey, R.H., Magid, D.J., McGuire, D.K., Mohler, E.R., Moy, C.S., Muntner, P., Mussolino, M.E., Nasir, K., Neumar, R.W., Nichol, G., Palaniappan, L., Pandey, D.K., Reeves, M.J., Rodriguez, C.J., Rosamond, W., Sorlie, P.D., Stein, J., Towfighi, A., Turan, T.N., Virani, S.S., Woo, D., Yeh, R.W., Turner, M.B., 2016. Heart disease and stroke statistics-2016 update a report from the American Heart Association. Circulation 1, 12-39. http://dx.doi.org/10.1161/CIR.0000000000000350.

Ngono Ngane, R.A., Mogtomo, M.K., Tabou, A.T., Nana, H.M., Chieffo, P.M., Bounou, Z.M., Etame, R.E., Ndifor, F., Biyiti, L., Amvam Zollo, P.H., Koanga Mogtomo, M.L.,
Tchinda Tiabou, A., Magnifouet Nana, H., Motso Chieffo, P.R., Mballa Bounou, Z. Ebelle Etame, R.M., Ndifor, F., Biyiti, L., Amvam Zollo, P.H., 2011. Ethnobotanical survey of some Cameroonian plants used for treatment of viral diseases. Afr. J. Plant Sci. 5, 15-21.

Paim, R.T.T., Benjamin, S.R., Rondina, D., Marques, M.M.M., de A. Viana, D., da C. Gonzaga, M.L., Vieira, I.G.P., Mendes, F.N.P., Rodrigues, P.A.S., Guedes, M.I.F., 2017 Antihypercholesterolemic effects of fruit aqueous extract of Copernicia prunifera (Miller) H. E. Moore in mice diet-induced hypercholesterolemia. evidence-Based complement. Altern. Med. 1-15. http://dx.doi.org/10.1155/2017/6376173.

Rodrigues da Silva, L., do V. Martins, L., Bantim Felicio Calou, I., Meireles de Deus, M. do S., Ferreira, P.M.P., Peron, A.P., 2015. Flavonóides: constituição química, ações medicinais e potencial tóxico. Acta Toxicol. Argent. 36-43.

Rodrigues, P.A.S., Guedes, I.F., Marques, M.M.M., Da Silva, I.N.G., Vieira Í, G.P., 2014. Hypoglycemic activity of coperniciacerifera mart. L. eaf powder extract in the treatment of alloxan-induced diabetic mice. Int. J. Pharm. Pharm. Sci. 6, 115-118.

Sashidhara, K.V., Kumar, A., Kumar, M., Srivastava, A., Puri, A., 2010. Synthesis and antihyperlipidemic activity of novel coumarin bisindole derivatives. Bioorg. Med. Chem. Lett. 20, 6504-6507. http://dx.doi.org/10.1016/j.bmcl.2010.09.055.

Schmitz, G., Orsó, E., 2015. Lipoprotein(a) hyperlipidemia as cardiovascular risk factor: pathophysiological aspects. Clin. Res. Cardiol. Suppl. 10, 21-25. http://dx.doi.org/ 10.1007/s11789-015-0074-0.

Simão, A., Precoma, D., Andrade, J., Correa Filho, H., Saraiva, J., Oliveira, G., Murro, A., Campos, A., Alessi, A., Avezum Junior, A., Miguel, A., Sousa, A., Lotemberg, A., Lins, A., Falud, A., Brandão, A., Sanjuliani, A., Sbissa, A., Santos Filho, A., Herdy, A., Polanczyk, C., Lantieri, C., Machado, C., Scherr, C., Stoll, C., Amodeo, C., Araújo, C., Saraiva, D., Moriguchi, E., Mesquita, E., Cesena, F., Fonseca, F., Campos, G., Soares, G., Feitosa, G., Xavier, H., Castro, I., Giuliano, I., Rivera, I., Guimaraes, I., Issa, J., Souza, J., Faria Neto, J., Cunha, L., Pellanda, L., Bortolotto, L., Bertolami, M. Miname, M., Gomes, M., Tambascia, M., Malachias, M., Silva, M., Iza, M., Magalhães, M., Bacellar, M., Milani, M., Wajngarten, M., Ghorayeb, N., Coelho, O., Villela, P., Jardim, P., Santos Filho, R., Stein, R., Cassani, R., D’Avila, R., Ferreira, R., Barbosa, R., Povoa, R., Kaiser, S., Ismael, S., Carvalho, T., Giraldez, V., Coutinho, W., Souza, W., 2013. I Diretriz Brasileira de Prevenção Cardiovascular. Arq. Bras. Cardiol. 101, 1-63. http://dx.doi.org/10.5935/abc.2013S012.

Soedamah-Muthu, S.S., Colhoun, H.M., Thomason, M.J., Betteridge, D.J., Durrington, P.N., Hitman, G.A., Fuller, J.H., Julier, K., Mackness, M.I., Neil, H.A.W., 2003. The effect of atorvastatin on serum lipids, lipoproteins and NMR spectroscopy defined lipoprotein subclasses in type 2 diabetic patients with ischaemic heart disease. Atherosclerosis 167, 243-255. http://dx.doi.org/10.1016/s0021-9150(02)00428-8.

Vandenburg, L.E., Wilder, E.A., 1967. Aromatic Acids of Carnauba Wax. J. Am. Oil Chem. Soc. 44, 659-662. http://dx.doi.org/10.1007/BF02680038.

Wilson, T.A., Nicolosi, R.J., Woolfrey, B., Kritchevsky, D., 2007. Rice bran oil and oryzanol reduce plasma lipid and lipoprotein cholesterol concentrations and aortic cholesterol ester accumulation to a greater extent than ferulic acid in hypercholesterolemic hamsters. J. Nutr. Biochem. 18, 105-112. http://dx.doi.org/10.1016/j. jnutbio.2006.03.006.

Xie, W., Zhao, Y., Du, L., 2012. Emerging approaches of traditional Chinese medicine formulas for the treatment of hyperlipidemia. J. Ethnopharmacol. 140, 345-367. http://dx.doi.org/10.1016/j.jep.2012.01.027.

Ziamajidi, N., Khaghani, S., Hassanzadeh, G., Vardasbi, S., Ahmadian, S., Nowrouzi, A., Ghaffari, S.M., Abdirad, A., 2013. Amelioration by chicory seed extract of diabetesand oleic acid-induced non-alcoholic fatty liver disease (NAFLD)/non-alcoholic steatohepatitis (NASH) via modulation of PPAR $\alpha$ and SREBP-1. Food Chem. Toxicol. 58, 198-209. http://dx.doi.org/10.1016/j.fct.2013.04.018. 